\title{
EAl Endorsed Transactions

\section{Exploring design guidelines for fostering citizen engagement through information sharing: Local playgrounds in The Hague}

\author{
Geertje Slingerland $^{1, *}$, Stephan Lukosch ${ }^{1}$, Tina Comes ${ }^{1}$, Frances Brazier ${ }^{1}$ \\ ${ }^{1}$ Faculty of Technology, Policy and Management, Jaffalaan 5, Delft, Delft University of Technology
}

\section{Abstract}

Citizens' engagement in their neighbourhood community is pivotal for cities to effectively deal with future transitions. Knowing what is going on and having access to the neighbourhood network are important conditions for this. Although prior research has studied ways to foster information sharing between citizens, the underlying assumptions and design choices are often not made explicit. This research identifies design guidelines for playgrounds: physical and virtual spaces where citizens can exchange information about their neighbourhood. A focus group, a workshop and a case study of an existing playground design were performed in The Hague, NL, the context of this research. A set of eight guidelines was identified, covering how to select playground locations, which information to include, and how to design the interaction between citizens. These guidelines inform designers how to create urban playgrounds for citizens to meet, interact, and collaborate to create engaged communities.

Received on 29 July 2019; accepted on 03 January 2020; published on 10 January 2020

Keywords: Citizen engagement, Information sharing, Interaction design, Playable cities, Playgrounds

Copyright $\odot 2020$ Geertje Slingerland et al., licensed to EAI. This is an open access article distributed under the terms of the Creative Commons Attribution license (http://creativecommons.org/licenses/by/3.0/), which permits unlimited use, distribution and reproduction in any medium so long as the original work is properly cited.

doi:10.4108/eai.13-7-2018.162636

\section{Introduction}

Cities are confronted with major transitions, like the energy transition or the digital transition. Further, they have to deal with societal challenges such as migration or poverty. These developments require citizens to work together and take collective action within their neighbourhood community [1, 2]. An important condition for this is that citizens are engaged with their local community [3-5], meaning that they are part of the neighbourhood social network $[6,7]$ and know what is going on [8]. Unfortunately, many big cities suffer from fragmentation: citizens do not interact with their neighbours $[9,10]$ and do not feel part of their neighbourhood community [11]. Overcoming this fragmentation is therefore high on the agenda, and many cities have started to experiment with policies to increase citizen engagement.

This paper focuses on the city of The Hague, which is the most fragmented city of The Netherlands [12,

${ }^{*}$ Corresponding author. Email: g.slingerland@tudelft.nl p. 52]. The Hague was part of the Rockefeller 100 Resilient City Program, and in their recently presented resilience strategy two aspects play a major role: (1) safe and empowered people and (2) liveable and cohesive neighbourhoods [13, p. 5]. To foster such cohesiveness [14], The Hague specifically strives to have citizens taking an active part in their local community to share and co-create initiatives that increase livability and safety of their neighbourhood. In order to engage in such a process, citizens need to exchange information with each other about what is happening in their community [15].

The Playable City [16, 17], where residents are empowered to participate, invites citizens to interact with each other in the virtual and physical environments in the city, creating new experiences, sharing with others, in playful ways. Introducing playful elements in the urban space was initially based on Huizinga's [18] Homo Ludens, in which play is something that happens voluntarily, is not about ordinary life, and for which fun is its only purpose. The earliest discussions on the playable city where thus mainly 
focused on using smart technologies to make the city a fun place, as these technologies can elicit social and humorous interactions between citizens [16].

At the same time, games have been used as a platform for studying complex systems [19] and learning [20]. In this case, games are an experimental, rule-based, interactive and social organisation, constituted by the players themselves, who learn by taking actions and by experiencing their effects through feedback mechanisms within the game [20]. While as such, within the game, players are immersed in playful activity, the impact and learning of the game can go beyond the play.

This paper takes this playable perspective, using technology to create fun, open and spontaneous interaction between citizen in the urban space, to increase neighbourhood participation and local information sharing. These interactions happen out on the streets in the public, the so-called Third Places [21]. From this perspective, Third Places, are, in fact, the playgrounds of the city: physical and virtual environments where citizens can interact and exchange information about the neighbourhood in a playful way. This transformation to a playground can take place by installing media architecture [22], like public displays $[23,24]$, or interactive installations, such as the Jokebox [25], which encourage citizens to interact with each other and to discuss neighbourhood issues important to them. Playgrounds could also be formed by the citizens themselves, as Angus et al. [26] explored with their Urban Tapestries application. Citizens create points-of-interest on a digital map and in the digital space share information about this location [27]. Such location-based information can be accessed by other citizens using their mobile phone, when they visit the location and can lower the threshold to participate in the local community by enhancing transparency [28]. These examples all show how public spaces in the city can become playgrounds using physical and digital augmentation.

However, as playground designs are highly contextspecific, it is challenging to transfer designs to other contexts. Even more so, because the underlying assumptions and design choices are often not made explicit. Therefore, this study aims to identify guidelines for designing playgrounds that foster local information sharing and neighbourhood participation. The contribution of this paper is a set of eight guidelines, prescribing how to select playground locations, which types of information to include, and how to design the interaction between citizens. These guidelines inform designers how to create urban playgrounds for citizens to meet, interact, and collaborate to create engaged communities.
The next section reviews literature on community engagement and empowerment, specifically focusing on interactive technology interventions that were designed for this purpose. The knowledge gap identified from this review is addressed with the presented study in the city of The Hague, further described in the method section. A focus group and workshop with citizens, and a case study of an existing playground design in The Hague were performed to identify the design guidelines from different perspectives. The results are described for each study and then translated to guidelines for design that are discussed in the conclusions.

\section{Background}

The question on how to design technology for community engagement and empowerment is extensively discussed in literature (see for example a review on empowerment in Human-Computer Interaction by Schneider et al. [29]). This paper specifically focuses on interactive technology designs which foster information sharing and citizen participation in an urban context. The next sections review prior work to define the main concepts used in this research (community, citizen participation and empowerment, and playgrounds in the smart city) and discusses what can be learnt in terms of design guidelines from previous interactive technology designs for citizen empowerment.

\subsection{Community}

A community can be defined by commonalities (e.g. common interest, locality, or social structure) $[30,31]$ or via identification of its members, who recognise their group is different to other groups [32, 33]. Due to information technology, neighbours are not restricted to local contacts any more, but rather form social relationships with people from outside their geographical community [6, 31, 33, 34]. Social relationships between neighbours have, therefore, become less common [10], leading to neighbourhood communities solely based on locality, rather than common interests or skills [31]. The communities discussed in this research are of this type: citizens living within the geographical boundaries of the neighbourhood are part of the community.

Such geographical communities are challenging in terms of engagement because they are heterogeneous with regard to interest and skills, which complicates a sense of coherence and community belonging [35]. In such communities, individuals provide less social support to each other [36]. The sense of belonging and identification with a community is even more difficult to achieve in highly volatile contexts, where residents frequently move in and out of the neighbourhood [10, 35], as is the case for The Hague. As a result, neighbours do not interact anymore on a regular basis and do not 
exchange information or stories about what is going on in the neighbourhood.

Technology has been described as key to preserve local social knowledge and to support information sharing and citizen engagement, especially in fluent neighbourhood communities [37]. Implementing playgrounds for information sharing and social interaction could improve the situation in which many citizens are disconnected from their direct living environment and have a reduced ability to change something in their community even if they want to. Citizens then experience a lack of agency, limiting their engagement in the community and willingness to change [38].

\subsection{Citizen participation and empowerment}

Citizens who take part in the neighbourhood become active and engaged [39], build trust towards governmental actors [40,41], and feel more at home in their neighbourhood [42]. As policymakers have started to recognise the benefits of citizens' contribution to the liveability and safety of the city [43], increasingly, policies are adopted to empower citizens to take responsibility for their neighbourhood [44].

What actions citizens take as a result of this responsibility can be very different. In citizen science, residents gather and analyse data to monitor various aspects in the environment, like air quality or biodiversity [45-48]. Notably, citizen science also aims at raising awareness for the environment, which eventually can influence and inform further engagement [49]. Citizens can as well take action by developing solutions for local problems or designing local citizen services $[50,51]$. For all these processes, access to information is vital. Information contributes to coherent understanding of the environment and the ability to act (agency), and information exchange allows the creation of connections and a social network [52]. Both of these aspects, situational awareness and social connections, are crucial conditions for citizen engagement and empowerment $[15,53]$.

However, citizen participation, especially from an empowerment perspective, has also been criticised. As Arnstein [54] showed with her ladder of participation, governments give away power to citizens, making citizen participation a top-down initiated process [55, 56]. Policies to create a partnership between citizens and the city are rarely in place [57], which limits the power and influence that citizens have. Within the urban context, the notion of power in citizen empowerment is thus understood as a power-over relation between two actors [29] where one actor (the government) has power over the other actor (the citizens), and this means the government can use their power (for example creating certain participation policies) to allow citizens to do something they would otherwise not be capable of (starting an initiative to improve the neighbourhood) [58]. This paper considers empowerment according to the definition of Zimmerman [59] as "a process in which people gain understanding and control over personal, social, economic, or political forces in order to take action to better their lives."

\subsection{Playgrounds in the smart city}

The many promises and high expectations associated to the smart city have resulted in many local governments labelling their city as 'smart' or adopting strategies to becoming a smart city [60]. Along with the proliferation and widespread use of the term 'smart city', there are many definitions of the concept. We follow Nam and Pardo [60], who conceptualise the smart city with three dimensions: technology, people, and institutions. In spite of the huge amount of research that focuses on technologies [60], without people who are using these technologies and appropriate governance, there is no smart city [61, 62].

The question is to what extent governments are the appropriate stakeholder to determine which technology is necessary in the smart city, since citizens might lack accessibility to it, as well as a lacking opportunity for citizens to have an influence on its design and outcome $[44,63,64]$. Other papers (e.g. $[5,17,25]$ ) stress the importance of not only focusing on topdown implemented technology that purely aims at efficiency, but rather to consider how these technologies can be used to empower and engage citizens to create a participatory city.

Smart technology in a participatory city is used to foster social interactions between citizens and evoke engagement of citizens with their environment, making it playable [16, 17]. Although initial attempts to introduce playful elements in the city were mainly focused on enabling fun experiences in the urban space [65], they also served other purposes. For example Street Pong and Dance Traffic Light both increased the amount of people that were willing to wait for a green traffic light, while interacting with this game [16]. The Social Stairs [66] is another well-recognised example of a design that was created from the perspective of fun, but also resulted in more people taking the stairs instead of the escalator. The application and study of critical play [67] or pervasive games embraces the notion of adding a purpose to play [65, 68]. Rather than having strict game rules, play and games become more open to spontaneity [65], moving beyond the magic circle of Huizinga [18]. Similar play behaviour is expected on the playgrounds proposed in this research. Bateson [69] and Caillois [70] both acknowledge that play is heterogeneous: play in terms of the Homo Ludens is defined by rules and without utility, while 
playful play is another play state in which people are more open, flexible, and spontaneous. The latter is the intention of playful playgrounds.

Installing interactive technology at specific locations in the neighbourhood transforms them into playgrounds where citizens meet and interact. For example, citizens share local information by tagging particular locations to share with other residents, through specifically designed service platforms $[26,39,71]$. Other options are to use gamified approaches where citizens share information about the neighbourhood while playing a game $[25,71-73]$.

\subsection{Designing playgrounds: What do we know}

The previous sections reviewed the current literature on designing playgrounds for citizen empowerment and engagement. Playgrounds, in our view, are similar to Third Places: public spaces in the city where citizens meet each other and interact, supported by interactive technology. These environments enable playful behaviour that is characterised by openness, curiosity, spontaneity, and engagement. The coming paragraphs discuss what we can learn from the current knowledge about playground design. Literature suggests that playgrounds can connect citizens by focusing on common interests [33, 34]. Citizens can share information on playgrounds with the purpose of addressing local concerns [45] or to preserve local knowledge [37]. The interaction on these playgrounds should be based on an 'embodied spatial interaction' approach [74], meaning that citizens use their body to interact with the physical environment. Literature also indicates that playful approaches stimulate citizens to interact on these playgrounds [16, 17], and stresses the importance of involving citizens in the playground design [60].

These insights cover different aspects on playground design: the role of the physical space, the information that is available or exchanged on the playground, the way citizens interact with each other and the playground environment, and the design process of these playgrounds. Although the suggestions from literature provide a starting point for the design, they do not specifically discuss how to deal with each of these aspects. For example, the physical space seems to play an important role [74], but what role exactly? Which parts of the physical space need to be taken into account to determine if a location is suitable to become a playground? Similar questions can be raised regarding the information that is presented at playgrounds and the interaction that is supported: how can citizens playfully share information on playgrounds [16, 17], and which local knowledge would need to be preserved? Finally, literature suggests a participatory approach for designing playgrounds, but it remains unclear how citizens can be involved in this process.

Although Bilandzic and Foth [74] already called a couple of years ago for design principles to shape meaningful technologies for spatial interactions and experiences, a knowledge gap remains: many papers do not explicitly mention their underlying design considerations and principles. As a result, while important aspects of playground designs have been identified, it remains unclear how designers should deal with each of these aspects. Therefore, this paper specifically focuses on these three playground aspects (location, information, and interaction) and involves citizens in the design process to identify guidelines on how to design each of these aspects.

\section{Method}

This research selected the city of The Hague (NL) as the context to study which guidelines can be identified to design playgrounds for information sharing. The Hague provides an ideal case for this research because the city suffers from fragmentation issues [12] and is thus looking for approaches to increase citizen engagement and create cohesive communities [13]. In order to study playground guidelines from different perspectives, a mixed method approach was used. This allows us to identify design guidelines through multiple phases, grounded in both qualitative and quantitative insights [75]. Therefore, this research took place in three different neighbourhoods in The Hague to create diverse cases that can be compared and contrasted to identify general playground guidelines [76].

An overview of the research procedure is given in Table 1. The next paragraph describes briefly the executed activities and how they relate. Thereafter, each activity is described in more detail under the corresponding header.

Three activities have been executed for this research: a focus group, workshop, and a case study. First, the focus group was organised with citizens from Bouwlust to investigate which locations are appropriate to share information, and which topics citizens found of interest to share on such playgrounds, resulting in an interactive digital prototype. Second, a workshop was held with citizens from Leidschenveen/Ypenburg to test the prototype. Citizens responses and use of the prototype provided further understanding of which information topics are of interest and in which situations citizens want to share information with each other. As a third and final step, an existing information sharing initiative in the neighbourhood of Segbroek was studied. This allowed us to check the insights from the previous research activities in a real-life situation, and to study how the guidelines that were identified so far are implemented in a real context. Together, these 
Table 1. Mixed methods were used to study design guidelines for playgrounds in three different research activities: focus group, workshop, and case study. While the focus group and workshop included participants, the case study did not involve citizens.

\begin{tabular}{llll}
\hline & Focus group & Workshop & Case study \\
Neighbourhood & Bouwlust & Leidschenveen/Ypenburg & Segbroek \\
Participants & 6 & 22 & 0 \\
Data collection & $\begin{array}{l}\text { Transcripts of recorded dis- } \\
\text { cussions }\end{array}$ & $\begin{array}{l}\text { Questionnaire, website logs } \\
\text { Video clips, scanning data, } \\
\text { Data analysis }\end{array}$ & $\begin{array}{l}\text { Qualitative coding } \\
\text { tile websites }\end{array}$ \\
& & $\begin{array}{l}\text { Qualitative and quantita- } \\
\text { Qualitative and quantitative } \\
\text { coding }\end{array}$ \\
\hline
\end{tabular}

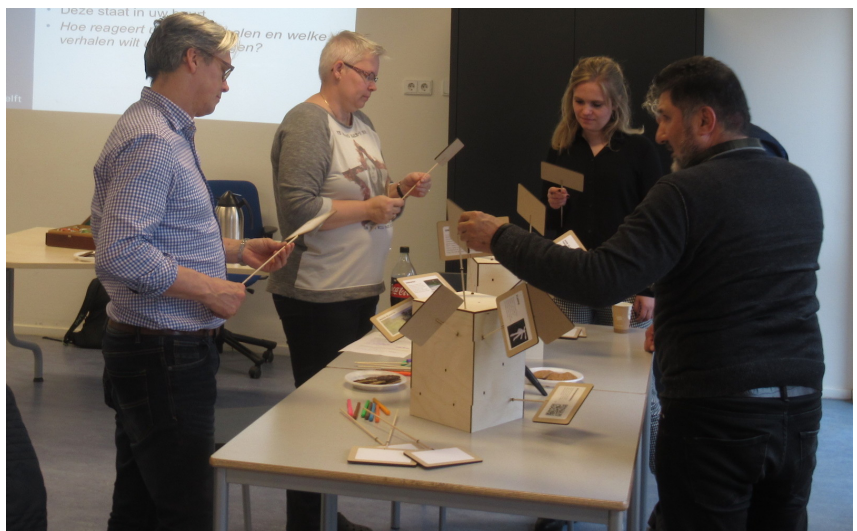

Figure 1. The first prototype was a wooden box with sticks on which stories about the neighbourhood were written. Participants considered and discussed these different stories during the focus group.

three research activities aimed to investigate which information citizens would like to share and receive, and on which locations. These insights provided the basis for the guidelines for playground design.

\subsection{Focus group}

The focus group was executed in Bouwlust, a neighbourhood in the south of The Hague. This area once started as an upper-class neighbourhood for civil servants, and now consists for about $70 \%$ of social housing. The neighbourhood is very diverse: almost $60 \%$ of the inhabitants are immigrants. The aim of the focus group was to identify which locations in the neighbourhood are most appropriate for sharing and creating specific types of information. Two playful probes were developed and used as the basis for discussion during the focus group, see Figure 1 and 2.

The first probe, Figure 1, was a wooden box with sticks on which various stories from the neighbourhoods were displayed. These stories were based on information shared on local social media pages, and both pictures and written text were used to communicate these stories. Empty sticks were available as well so that participants could add their own stories.

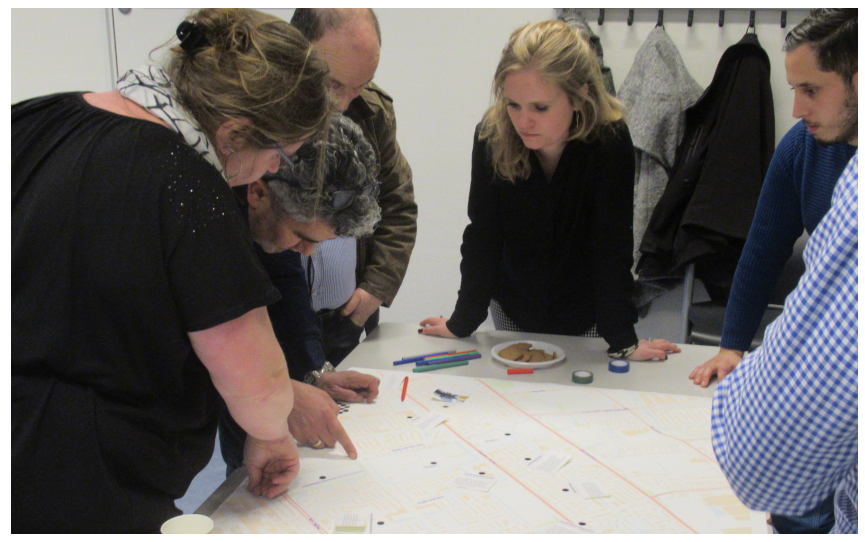

Figure 2. The second prototype was a map of the neighbourhood on which participants could add locations that are relevant to them.

Participants first freely explored the stories and after 10 minutes, discussion was started to focus on the specific neighbourhood needs, expressed by the participants, in relation to the probe. Thus, which stories participants found intriguing, with whom they would share these stories and what other stories they would be interested in.

The second probe was a printed map of the neighbourhoods, see Figure 2. On the map, specific locations and information were already marked for participants to consider. Materials were provided for them to mark other locations as well. As in the first prototype, participants first worked on this task within the prototype, and discussion followed on which locations were still missing on the map, and why these locations were considered to be appropriate.

Participants. Purposive sampling [77] was used to recruit citizens for the focus group. The criteria specified that citizens needed to live in Bouwlust and be interested in contributing to the quality of life and safety in their neighbourhood. Several community activities and spaces were visited to come into contact with citizens and build a citizen network. From these efforts, six citizens were recruited to participate in the focus group: two women and four men, three citizens 
with a Turkish background and three with a Dutch background.

Data collection and analysis. The focus group discussions were recorded and transcribed for analysis. Thematic content analysis [78] was performed on the transcript, by using inductive coding to select and code data fragments that said something about which locations participants found suitable as playgrounds, and what information they perceived as appropriate to share. Furthermore, the discussions were analysed to understand how the information within the probes fostered information sharing and supported participants to build on each others stories.

\subsection{Workshop}

The workshop was executed in LeidschenveenYpenburg, a neighbourhood in the south-east part of The Hague with about 50.000 inhabitants. The area is relatively new, about 20 years old, and mainly consists of owner-occupied properties. The neighbourhood is specifically home to young families from middleto upper-class socio-economic backgrounds. The community has an active neighbourhood watch, a group of citizens who occasionally walk through the neighbourhoods to increase safety, and to look out for each other.

The workshop aimed to identify which information citizens would like to be shared when and where, following on the insights from the focus group. In particular, the question was addressed whether the need for information sharing depends on specific circumstances such as a neighbour asking for help. To this purpose, seven different scenarios (see Table 2) were developed to explore if the scenario influences the need for information sharing between neighbours. These scenarios are based on the insights from the focus group that describe different information categories that were found most interesting by citizens.

Table 2. The seven scenarios that were included in the workshop reflected three different information categories identified in the focus group.

\begin{tabular}{ll} 
Scenario & Category \\
\hline $\begin{array}{l}\text { Sick child } \\
\text { Burglaries } \\
\text { Housekeeper }\end{array}$ & Share personal experience \\
\hline $\begin{array}{l}\text { Neighbourhood } \\
\text { initiative }\end{array}$ & Organising activities \\
Community space & \\
\hline $\begin{array}{l}\text { Lonely neighbour } \\
\text { Cooking neighbour }\end{array}$ & $\begin{array}{l}\text { People from the } \\
\text { neighbourhood }\end{array}$
\end{tabular}

Design of the seven scenarios. The prototype for the workshop was a digital interactive website, see Figure

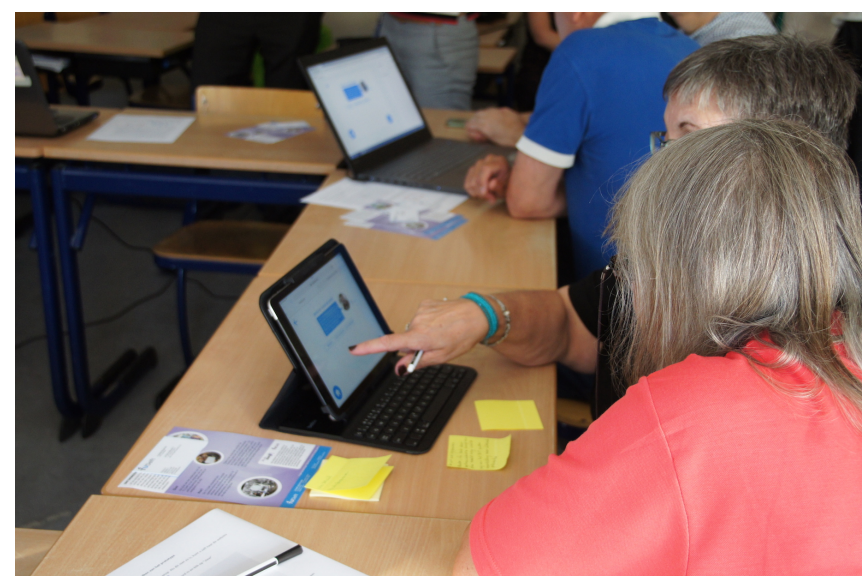

Figure 3. Participants are reading and responding to the stories in the digital prototype.

3. It displayed various questions, problems or stories of citizens presented in seven information sharing scenarios (see Table 2). In the scenarios on the sick child, the housekeeper, and burglaries, fictive neighbours respectively ask for specific suggestions for finding a babysitter, a housekeeper, or how to protect their home against burglars. In contrast, in the scenarios on the neighbourhood initiative and community space, a representative of a citizen initiative asks neighbours to think along and participate in their activities. Finally, the two scenarios on the lonely neighbour and cooking neighbour present the story of a fellow citizen and do not ask for a specific response.

These pieces of information to create the scenarios were based on actual challenges and developments in The Hague, some identified during the previous focus group. This information could be sorted by the participants on the basis of specific citizen (personal), topics (theme), or position on a map (location). In addition to being able to view information, participants could also create new information or respond to one of the questions or problems stated on the website.

Participants. A similar approach as for the focus group was used to recruit participants for the workshop. Citizens were made aware of the event through gatekeepers and 'Burgernet', a government-run safety alert platform. This resulted in 21 citizens that participated in the workshop (14 males and seven females, ethnic background was in this case not recorded).

Workshop procedure. The workshop took place in two rounds with ten and eleven citizens respectively. Citizens took place behind a laptop in groups of two, and received a brief instruction on the functionality of the prototype. For about 20 minutes, citizens could interact with the prototype, viewing different questions, stories, and problems of neighbours prepared by the 
researchers, and respond to these online. After that, participants were asked to fill out a questionnaire to assess each scenario on the relevance of the information, to what extent the scenario would lead to interaction, and whether the scenarios would be applicable in their neighbourhood.

Data collection and analysis. Data was collected from the questionnaire and the responses written in the digital prototype. Both qualitative and quantitative analysis was performed on this data. Qualitative coding was used to categorise the responses of citizens to each scenario and quantitative frequency analysis was performed to count responses. Further, the questionnaire responses were analysed based on frequency as well, for example calculating mean scores on how each scenario stimulates information sharing amongst citizens.

\subsection{Case study Tegelweetjes}

The case study took place in Segbroek, a diverse neighbourhood with around 60,000 inhabitants in the mid-west part of The Hague. A large portion of the residents has lived there for over 30 years, but there are also many expats who move in and out frequently. Albeit the dynamics, several community engagement initiatives are in place, such as the local platform CultuurKwartier ${ }^{1}$ which connects different neighbourhood initiatives. For example, they organised a theatre performance reflecting the different religions present in the neighbourhood.

The focus group and workshop illuminated potential playground locations, which information topics are of interest to share, and under which circumstances information sharing is relevant. To further identify how playgrounds can be designed, these findings were compared to a real-life playground that fosters information sharing amongst citizens. A citizen initiative in The Hague was identified and studied to validate and complement the findings so far. The initiative is called Tegelweetjes $^{2}$ (Dutch for Knowledge Tiles) and has selected 50 locations in the neighbourhood Segbroek to place QR codes on tiles. Upon scanning these codes, a webpage is opened that displays information (in text or with pictures) about that specific locations. New information can be added to the tiles by contacting the initiator of Tegelweetjes.

Each of the 50 locations was visited during two field trips, which lasted about 3.5 hours in total. During the visits, video clips were taken of the environment surrounding the tile for later analysis. The video clips, the information connected to the QR codes, and

\footnotetext{
${ }^{1}$ https://www.hetcultuurkwartier.nl/

${ }^{2}$ https://www.tegelweetjes.nl/
}

scanning frequency of $\mathrm{QR}$ codes were used to test hypotheses on which type of locations and information are appropriate for playground design.

Data collection and analysis. For each knowledge tile location, the following data was collected: (1) a video clip of the location, (2) available information on the webpage that opens upon scanning the QR code, and (3) the scanning frequency. The video clips were watched to map the surrounding environment of the knowledge tiles, using the location types and characteristics as found in the focus group and workshop (see Table 5 in Results), but also identifying new types and characteristics. The information on the webpages for each knowledge tile was studied to sort the information presented at each tile, based on categories found in the focus group and workshop, and to identify new categories as well. As a result, each knowledge tile was classified based on location and information categories.

An overview of all variables included in the analysis is shown in Table 3. The scanning frequency data was received from the initiator of Tegelweetjes in June 2019 and consisted of the 50 tile locations and how often each QR code at that location had been scanned. The data sheet was complemented with the amount of stories per tile (most tiles present more than one story), location type, location diversity (the number of different utilities to be spotted), characterisation of location, information topic(s), and the topic diversity. The scanning frequency only showed the number of scans per tile six months the tiles were installed (not how it varied over time). Therefore, the other variables were also considered static and measured after six months, while for example the number of stories per tile did vary over time (stories were added to tiles). In contrast, the locations of the tiles and total number of tiles did not change over the data collection period.

Three statistical tests were used to study the relationships between the scanning frequency and the other variables (see Table 4 for the statistical tests and alternative hypotheses used). One-way ANOVA and Kruskal Wallis tests were used to analyse the difference in scanning frequency between various information topics, locations types, and location characteristics. Spearman's correlations were used to analyse relationships between the scanning frequency and other variables, such as the number of stories available at one tile, the topic diversity, and location diversity.

\section{Results}

Three research activities were executed to study guidelines for playground design: focus group, workshop, and case study. The next section describes the results of each of the activities and finally presents the design guidelines that follow from the results. 
Table 3. The variables that were used in the case study of Tegelweetjes. Each variable is explained and the measurement level is given.

\begin{tabular}{|c|c|c|}
\hline Variable & Description & Measurement level \\
\hline Scanning frequency & $\begin{array}{l}\text { The number of scans after six months } \\
\text { (January-June 2019) }\end{array}$ & Ratio \\
\hline Number of stories & The number of stories per tile & Ratio \\
\hline Location type & $\begin{array}{l}\text { Categorisation of tile locations based } \\
\text { on type }\end{array}$ & Nominal \\
\hline Location diversity & $\begin{array}{l}\text { The number of different physical } \\
\text { locations around one tile }\end{array}$ & Ratio \\
\hline Location characteristics & $\begin{array}{l}\text { Categorisation of tile locations based } \\
\text { on its characteristics }\end{array}$ & Nominal \\
\hline Information topic & $\begin{array}{l}\text { Categorisation of themes that the tile } \\
\text { stories cover }\end{array}$ & Nominal \\
\hline Topic diversity & $\begin{array}{l}\text { The number of different topics covered } \\
\text { in one tile }\end{array}$ & Ratio \\
\hline
\end{tabular}

Table 4. Statistical tests and their hypotheses, performed to study relationships between variables.

Alternative hypothesis
The mean scanning frequency
does differ between different
information topics
There is a relationship between
scanning frequency and topic
diversity
There is a relationship between
scanning frequency and number
of stories
The mean scanning frequency
does differ between different
location characteristics
The mean scanning frequency
does differ between different
location types
There is a relationship between
scanning frequency and location
diversity

Analysis

One-way

ANOVA

Spearman's

correlation

Spearman's

correlation

Kruskal

Wallis

One-way

ANOVA

Spearman's correlation

\subsection{Focus group}

The outcomes of the focus group can be structured into four aspects: (1) which type of locations and location characteristics citizens mentioned for playgrounds, (2) what triggered citizens to share information with each other and to build on each others stories, (3) what would be advantages of increased information sharing, and (4) which information topics citizens found interesting to discuss.

Location types and characteristics. Table 5 shows which locations types and characteristics were identified ranging from community spaces to planned construction sites. Religious places, such as churches and mosques

were mentioned most often as relevant locations. Further, nine characteristics which describe a potential playground location were revealed. Table 5 also illustrates which characteristics citizens associated with each location type. Note that only characteristics explicitly mentioned by the participants have been allocated to a location type, thus characteristics logically fitting a location type (e.g. schools also being social places) are not stated here when citizens did not mention them.

Three key characteristics, based on how often they were named, were identified:

1. Amount of activities that are taking place on the location (discussed seven times). For example, the local theatre organising cultural events, or sports clubs that have weekly training and matches.

2. Amount of stories which can be told about the location (discussed five times). This can be a fun fact, such as how many people pass by everyday, or a story on how the place has developed over time.

3. Amount of citizens visiting the location (discussed four times). This means that appropriate playground locations can differ for individual citizens, depending on where they regularly frequent.

These locations do not necessarily have to be in the neighbourhoods citizens live in. For example, neighbourhoods in which their children's schools are situated, are neighbourhoods citizens traverse on an almost daily basis: participants expressed interest in knowing more about these neighbourhoods and their local activities.

In sum, an overall condition for playground locations is that citizens need to identify with them. Places that citizens often go to become their frame of reference and 
Table 5. In total, 11 location types were mentioned (in parentheses how often they were mentioned) and reflect various characteristics a location should have to be a potential playground.

\begin{tabular}{ll} 
Location type (frequency) & Characteristics \\
\hline Religious places (5) & $\begin{array}{l}\text { activities } \\
\text { proximity } \\
\text { relevance for neighbours }\end{array}$ \\
\hline Historic places (3) & $\begin{array}{l}\text { serendipity } \\
\text { familiarity } \\
\text { fun facts }\end{array}$ \\
\hline Theatre (3) & activities \\
\hline Planned constructions (3) & fun facts \\
\hline Schools (3) & visit often \\
& activities \\
\hline Sports clubs (3) & activities \\
& fun facts \\
\hline Shops (2) & visit often \\
\hline Community spaces (2) & activities \\
& fun facts \\
\hline Associations (1) & activities \\
& social \\
\hline Streets (1) & fun facts \\
& visit often \\
\hline Architectonic buildings (1) & fun facts
\end{tabular}

help them to orient themselves in the neighbourhood. For citizens to consider a location as a playground to share information, they need to feel familiar and identify with the place.

Information sharing triggers. The main trigger for citizens to start sharing information was whether they identified with the presented information and stories. The prototypes on which participants reflected contained several stories and other information about the neighbourhood of the participating citizens. Participants started to build on the stories provided from the prototypes illustrated by two prototypical examples: The first situation concerns the story and picture of a local hero who cleans up the neighbourhood, presented in the prototype. One participant took this particular information as an example to reflect on the importance of diversity in the neighbourhood and that having pictures of the different people that live there would be a way to celebrate this diversity. The second situation, recorded to happen 19 times, is that participants would add to what was being said based on their own knowledge of the neighbourhood or a personal experience they have had. For example, at a certain point the group discussed the local theatre and one participant started to tell that the theatre building used to be a school and what kind of activities had been organised there. This situation was sometimes triggered by the information presented in the probe, and sometimes resulted from the discussion that was going on. These findings indicate that information sharing can be triggered when citizens relate to and identify with the information, and have unique experiences about it.

Purpose of sharing. Citizens stated three main reasons for sharing information about the neighbourhood with each other. The first reason was that sharing information is relevant to know what is going on in the neighbourhood, recorded six times in the analysis. Second, citizens mentioned five times that sharing information would lower the boundaries of making contact with others or visiting unfamiliar places. For example, one participant expressed her interest for the Islam, but felt reluctant to enter a mosque as she was not sure if she could just do that. Being able to access information about visiting this mosque or being connected to someone from the mosque would lower the barrier for her to engage with this part of her neighbourhood. The third reason to share information is related to the relevance of the information: whether citizens find the information interesting.

Information topics. The results so far indicated that citizens want to identify with the local information that is shared on the playgrounds, and that the information must be of interest. The analysis indicated 21 topics that citizens mentioned in the discussion, of which five key topics were recorded five times or more:

1. Organising activities in the neighbourhood (discussed ten times), for example citizens taking initiative to organise something, or promoting activities that are already being organised.

2. History of the neighbourhood (discussed nine times), for example stories on how the neighbourhood developed or pictures of what the neighbourhood used to look like.

3. People who live in the neighbourhood (discussed eight times), for example stories or pictures introducing which people live in the neighbourhood.

4. Religion (discussed five times), for example sharing and participating in rituals that are part of different religions.

5. Fun facts about the neighbourhood (discussed five times), for example the meaning of street names or the story behind landmarks in the neighbourhood.

Even though participants were interested in these topics, they were reluctant to share their own personal story when asked specifically by the facilitator. However, as discussed before, the workshop discussion records citizens building on each others stories by 
adding their own knowledge and complementing the discussion with their personal experiences, but in these cases participants were probably not aware that they were doing this.

\subsection{Workshop}

The following paragraphs describe (1) how the insights from the focus group informed the workshop design, (2) what type of responses the different scenarios evoked, and (3) which scenario resulted in the highest number of interaction between citizens. The workshop focused on identifying in which scenarios citizens are inclined to share information with each other. In other words, eliciting the contextual conditions of sharing information on playgrounds.

Translating focus group insights to workshop design. As the focus group revealed the importance of citizens relating to and identifying with the information presented to them, the different scenarios in the workshop covered various topics to ensure participants would relate to at least one of the scenarios. The focus group showed that citizens were inclined to contribute to the discussion when they could add their own personal knowledge and experience. Three scenarios (housekeeper, sick child, and burglaries) were formulated in such a way that citizens could use their own knowledge to reply to the information given. Furthermore, information on organising activities and people of the neighbourhood were found to be most interesting to citizens during the focus groups and, therefore, further explored during this workshop. History was also a popular topic, but because the participants in the workshop came from a relatively new neighbourhood (less than 20 years old) this topic was less relevant for this group, and not selected. The scenarios on the neighbourhood initiative and community space are based on the topic organising activities, while the scenarios on the lonely neighbour and cooking neighbour were based on the people from the neighbourhood topic.

Response types. Table 6 shows how many responses each scenario got, and what type of responses were given. In line with the results of the focus group, the scenarios that were based on sharing personal experience evoked most responses: 22 in total. The other two categories had both nine responses. This strengthens the finding that information sharing can be fostered when citizens can add their own knowledge and personal experiences to the discussion, especially in cases when a citizen directly asks for help.

The way citizens responded to each scenario can be divided into four types. Table 7 presents these types and for which scenario they were observed most often. The first type of response is referring to institutions. This response type was most observed for the organising activities and share personal experience scenario categories (both three times). For example, one response to the neighbourhood initiative scenario was the suggestion to visit the community centre or the local municipality because they would be able to help the citizen out. In such a case, citizens do not help their neighbour themselves, but rather refer to a formal institution that should take this responsibility.

The second response type is offering help, and naturally this means that citizens would offer direct help to their neighbour. For example, in the case of the housekeeper, one participant offered to help out with the household. Offering help was observed most in the share personal experience category scenarios (four times).

The third type of response is providing tips, which relates to adding knowledge to the presented information and consequently was found to be the most frequent way participants replied to a scenario. This response type was logically observed eight times for the share personal experience scenario category. In such cases, participants would come with concrete suggestions on what the neighbour could to do solve the problem.

The final response type is making connections and this was most observed in the people from the neighbourhood based scenarios (five times). With such a response, participants would create links between the neighbour and another citizen, an initiative, or themselves.

Contribution to citizen engagement and information sharing. The questionnaire provided insight in the opinions of participants on the seven scenarios, especially focused on how they might increase citizen engagement and information sharing. The results are summarised in Table 8 . When asked which scenarios would increase citizen engagement the most, scenarios from the organising activities and people from the neighbourhood categories were both selected 18 times. The scenarios on share personal experience were selected 16 times. This indicates that citizens find all three scenario categories relevant and important for increasing citizen engagement.

With regard to increasing information sharing amongst citizens, Table 8 shows that the scenario on burglaries would, according to participants, lead to most information sharing (mean score of 3.95), while the sick child scenario would be the least motivating for sharing information (mean score of 1.95). Interestingly, these scenarios are both scenarios in the share personal experience category. When considering the average means of the three scenario categories, the means all vary around 3 , showing that all three information types are equally important in fostering information sharing, according to the participants. 
Table 6. Table shows how often participants replied to each scenario and what response type was evoked most often for each scenario category. Scenario categories are printed in italic.

\begin{tabular}{ccc} 
Scenario & Amount & Response type \\
\hline Share personal experience & 22 & Referring to institutions, offering help, providing tips \\
Sick child & 6 & \\
Burglaries & 8 & \\
Housekeeper & 7 & Referring to institutions \\
Organising activities & 9 & \\
Neighbourhood initiative & 3 & Making connections \\
Community space & 6 & \\
\hline People from the neighbourhood & 9 & \\
Lonely neighbour & 5 & \\
Cooking neighbour & 4 &
\end{tabular}

Table 7. Table gives an overview of the four different response types and for which scenario they were observed most often.

\begin{tabular}{ll} 
Response type & Scenario (frequency) \\
\hline Referring to institutions & $\begin{array}{l}\text { Organising activities } \\
(3), \text { Share personal } \\
\text { experiences (3) }\end{array}$ \\
Offering help & $\begin{array}{l}\text { Share personal experi- } \\
\text { ence }(4)\end{array}$ \\
Share personal experi- \\
ence (8) \\
Making connections & $\begin{array}{l}\text { People from the neigh- } \\
\text { bourhood (5) }\end{array}$
\end{tabular}

Finally, participants were asked in the questionnaire to what extent the different scenarios were applicable to their own neighbourhood. The sick child scenario was again found the least applicable, seven participants stated it would be applicable for their neighbourhood. The burglary scenario was found to be the most applicable, 17 participants mentioned this. For the other scenarios, the range varied between eight to eleven people replying it would apply to their neighbourhood, showing that each scenario was relevant to several participants.

\subsection{Case study}

The next paragraphs describe the final iteration on location types, location characteristics, and information topics to be of relevance for designing playgrounds for citizen engagement. The analysis focused on further defining these three playground elements. In addition, it aimed to refine the insights gathered in the workshop on which contexts of sharing information (combining location and topic) evoke most interaction and citizen engagement.

Refining location types. Both the video recordings and Google maps were used to allocate location types to each of the tiles. One tile was classified with four types, all other locations had three or less, and five locations could not be classified within these types. More than one location type was assigned to the tile when, for instance, there is both a religious building and a school around a tile.

Table 9 presents the results of the statistical analysis that were performed. The results of the ANOVA show a non-significant effect of location types on scanning frequency, $\mathrm{F}(15,34)=1.16, \mathrm{p}=0.348$. This means that, with the location types indicated so far, there seems to be no difference in terms of how often the QR code is scanned. Because a relatively high number of location types $(18$, because seven extra categories were created for the locations that fitted into more than one of the eleven location types) was used for the ANOVA, there are not that many cases per type.

A Spearman's correlation was performed as a next step. The difference in location was now determined by the number of types the tile was mapped on, ranging from 0 to 4 (location diversity). The analysis confirms the ANOVA result, as no significant relationship is found: $r=0.071, p=0.622$. This strengthens the insight that type of location, in terms of physical buildings and objects determining the utility of the place, does not make a difference to whether a location is appropriate to become a playground.

Refining location characteristics. Location characteristics (see Table 5) had to be divided into two types: ones that are objective and independent of the individual citizen, and ones that are personal, dealing with perceptions and experiences of citizens. Although eight characteristics were mentioned in the focus group, only four (the ones that are objective) could be used to categorise the QR tile locations:

1. Social: whether the location allows to meet neighbours,

2. Visit often: whether the location is a place where people pass by or come often, 
Table 8. Table shows how often participants selected each scenario when asked if it would contribute to citizen engagement. Further, it reports the mean score from the Likert 5-point scale question on how much each scenario would increase information sharing (1 being not at all, and 5 being sharing a lot of information).

\begin{tabular}{ccc} 
Scenario & Citizen engagement & Information sharing (mean score) \\
\hline Share personal experience & 16 & 2.67 \\
Sick child & 2 & 1.95 \\
Burglaries & 13 & 3.95 \\
Housekeeper & 1 & 2.11 \\
\hline Organising activities & 18 & 3.19 \\
Neighbourhood initiative & 10 & 3.11 \\
Community space & 8 & 3.26 \\
\hline People from the neighbourhood & 18 & 2.74 \\
Lonely neighbour & 10 & 2.53 \\
Cooking neighbour & 8 & 2.95 \\
\hline
\end{tabular}

Table 9. Statistical analysis to study whether scanning frequency significantly differs for different location types, and whether there is a relationship between scanning frequency and number of locations types (location diversity).

\begin{tabular}{ccccc} 
Comparison & $\mathrm{dF}$ & $\mathrm{F}$ & $\mathrm{p}$ & $\mathrm{r}$ \\
\hline Location type & $\mathrm{F}(15,34)$ & 1.158 & 0.348 & \\
Location diversity & & & 0.622 & 0.071 \\
\hline
\end{tabular}

Table 10. Results of the Kruskal Wallis test to study whether scanning frequency significantly differs between different location characteristics.

\begin{tabular}{cccc} 
Comparison & $\mathrm{dF}$ & $\mathrm{H}$ & $\mathrm{p}$ \\
\hline Location characteristics & 6 & 13.60 & 0.034 \\
\hline
\end{tabular}

3. Fun facts: whether the location has an interesting story,

4. Activities: whether activities are happening at the location.

The other characteristics are related to personal perception of an individual citizen. For example for familiarity, it depends on the citizen whether (s)he is familiar with the location. These characteristics could, therefore, not been considered for the analysis.

The results of the Kruskal Wallis test are shown in Table 10 and show there is a significant difference between characteristics for how often tiles were scanned, $\mathrm{H}(6)=13.60, \mathrm{p}<0.05$. Pairwise comparisons were made to see which characteristics significantly differ from each other and found only a significant difference between tiles characterised as social, and tiles characterised as both social and often visited. Tiles only characterised as social are scanned about 28 times less than locations that are both social and visited often. Whether or not a location is crowded and visited often, seems to have an effect on the amount of scans.
Table 11. Statistical analysis to study whether scanning frequency significantly differs between information topics, and whether there is a relationship between scanning frequency and number of information topics (topic diversity) and stories.

\begin{tabular}{ccccc} 
Comparison & $\mathrm{dF}$ & $\mathrm{F}$ & $\mathrm{p}$ & $\mathrm{r}$ \\
\hline Information topics & $\mathrm{F}(12,36)$ & 0.684 & 0.756 & \\
Topic diversity & & & 0.027 & 0.315 \\
No. of stories & & & 0.002 & 0.421 \\
\hline
\end{tabular}

Refining information topics. Four main information themes were derived from the 21 information topics identified earlier in the focus group and workshop. They partially overlap with the five key topics from the focus group, which were distinguished based on discussion frequency. The four main themes are:

1. Information on activities, like activities organised in the neighbourhood.

2. Information about people, such as personal stories of (former) residents, cultural or religious stories.

3. Funny or surprising stories about the neighbourhood, for example about the meaning of street names or landmarks.

4. Information about the development of the neighbourhood, concerning the history but also future plans.

The four information themes were used to cluster the information available on each QR code website. Most tiles (40) contain multiple stories about the surrounding environment, which is why some tiles cover more than one theme. All tiles could be divided within those themes, indicating it is exhaustive.

Table 11 shows the results of the statistical comparisons that were made. The analysis did not indicate a significant result, $\mathrm{F}(12,36)=0.68, \mathrm{p}=0.756$. 
This means no evidence was found for a significant difference between information theme and scanning frequency.

As a final step, the relationship between the diversity of information available at one tile (topic diversity) and scanning frequency was studied. Spearman's correlation shows a significant moderate positive relationship between those two variables: $\mathrm{r}=0.32, \mathrm{p}$ $<0.05$. This means that QR codes are scanned more often when more than one theme is presented on the corresponding website. Another correlation analysis was performed between the amount of stories on one tile, and the scanning frequency, to check the previous result. This one shows a strong significant positive relationship, $\mathrm{r}=0.42, \mathrm{p}<0.01$. This means that when there are more stories and themes available on the tile, the QR code is also scanned more often.

\section{Discussion}

This section presents and discusses the guidelines for designing playgrounds that follow from the results of the three research activities.

\subsection{Deriving the guidelines}

The guidelines for playground design are derived from the focus group, workshop, and case study findings. A brief summary is given here of what was found for each research activity and provided the basis for the presented guidelines. When a finding was reported in at least two of the three research activities, it is presented here as a guideline. Guidelines are formulated as normative statements for the design of playgrounds. They can be used to set requirements for a specific context and, when found relevant as well in other cities, can evolve to design patterns [79].

The main result of the focus group was the identification of different location types, characteristics and information topics which citizens need to identify with in order to become engaging. Further, the focus group showed that citizens are eager to respond to information if they can add using their own experience and that access to information lowers barriers to social interaction. The workshop insights build further on this by revealing four different interaction types that citizens can engage in. Moreover, the workshop elaborates on which information topics citizens find most interesting to discuss with neighbours and contribute most to community engagement. Finally, the case study deepened the understanding of the role of information topics and location characteristics and types in information sharing between citizens.

\subsection{Guidelines for playground design}

A set of eight guidelines is presented in Table 12 . Our guidelines cover the playground aspects locations, information, and interaction between citizens. The following section presents the guidelines and reflects how they match the current literature.

Location guidelines. Choosing appropriate locations is a vital step for creating playgrounds that foster interaction between citizens. This study showed that often visited locations will naturally draw people to them, providing an environment for social interaction. Brignull and Rogers [80] identified this as the honeypot effect: drawing attention to the playground and encourage people to engage. Previous playground designs such as the Jokebox [25] also choose places with many people around to implement their designs. Such locations are probably located centrally in the neighbourhood and because much is happening there, there are also stories to tell about these places. Therefore, crowded places are a good starting point to select locations for playgrounds.

The second guideline on locations states that playgrounds do not need to be on locations with specific utilities, such as shops. Albeit others also suggested to choose locations where citizens already meet each other, independent of what is there $[81,82]$, this finding was not expected. In the focus group, citizens extensively discussed about locations based on utility. From that discussion, religious buildings, community spaces, and shops seemed to be of importance to be located at playgrounds, but this was not confirmed in the workshop nor case study. The case study even indicated that these location types did not make a difference on interaction quantity, leading to the guideline that location utility does not need to be considered when selecting playground locations.

Finally, several characteristics were found that describe a suitable playground location. Four of those are dependent of citizens' perception (proximity, relevance, serendipity, familiarity) and can therefore not be generally assigned to a location, but need to be considered from citizens' perspective. This guideline inherently suggests a participatory design approach [83] for selecting locations. Other articles [81, 84] also found that factors such as familiarity foster social interaction. For example, Han et al. [85] report that citizens who lived longer in a town were adding more informative content compared to newcomers in their information sharing system. The other four characteristics (activities, social, fun facts, visit often) are independent and can be assigned to locations by the designer.

Information guidelines. Information within the themes of activities, people, neighbourhood development, and fun facts are of interest on playgrounds. The first theme is about activities that are happening on the playground location, or could potentially be organised there. The second theme concerns the people who currently live or 
Table 12. Design guidelines for playgrounds that have been identified in this research. For each guideline, the table states which playground aspect it describes and from which research activities it was derived from.

\begin{tabular}{|c|c|c|}
\hline Playground aspect & Guideline & Derived from \\
\hline \multirow[t]{3}{*}{ Location } & $\begin{array}{l}\text { Playgrounds on locations that are central and often visited are } \\
\text { more prone to neighbours interacting with it. }\end{array}$ & $\begin{array}{l}\text { Focus group, case } \\
\text { study }\end{array}$ \\
\hline & $\begin{array}{l}\text { Playground locations do not need to have specific utilities in } \\
\text { terms of buildings. }\end{array}$ & $\begin{array}{l}\text { Focus group, case } \\
\text { study }\end{array}$ \\
\hline & $\begin{array}{l}\text { Whether a location is appropriate as a playground is partially } \\
\text { dependent on whether citizens relate to and identify with it, } \\
\text { and partially dependent of characteristics describing the location } \\
\text { itself (activities, visit often, fun facts, social). }\end{array}$ & $\begin{array}{l}\text { Focus group, case } \\
\text { study }\end{array}$ \\
\hline \multirow[t]{2}{*}{ Information } & $\begin{array}{l}\text { Information within the themes of activities, people, neighbour- } \\
\text { hood development, and fun facts are of interest to share. }\end{array}$ & $\begin{array}{l}\text { Focus group, work- } \\
\text { shop, case study }\end{array}$ \\
\hline & $\begin{array}{l}\text { By lowering barriers to information access on playgrounds social } \\
\text { interaction between citizens can be fostered. }\end{array}$ & $\begin{array}{l}\text { Focus group, work- } \\
\text { shop, case study }\end{array}$ \\
\hline \multirow[t]{3}{*}{ Interaction } & $\begin{array}{l}\text { To elicit first interaction on the playground, the location and } \\
\text { physical surrounding is more important to consider than which } \\
\text { information is shared. }\end{array}$ & $\begin{array}{l}\text { Focus group, case } \\
\text { study }\end{array}$ \\
\hline & $\begin{array}{l}\text { Citizens are eager to respond to information and stories with } \\
\text { which they identify and can add from their own personal } \\
\text { experience. }\end{array}$ & $\begin{array}{l}\text { Focus group, work- } \\
\text { shop }\end{array}$ \\
\hline & $\begin{array}{l}\text { The interaction between citizens on playgrounds can be designed } \\
\text { to refer to institutions, offer help, provide tips, or make } \\
\text { connections. }\end{array}$ & $\begin{array}{l}\text { Focus group, work- } \\
\text { shop }\end{array}$ \\
\hline
\end{tabular}

used to live on the playground. The third theme is about neighbourhood development and physical evidence of these stories (e.g. memorial sign or old building) are to be found on the playground. Finally, fun facts are surprising, funny stories about the playground location, not reflected in any of the other themes. An example is the meaning of the street name of the playground. Information that falls within these four themes are all suitable to be shared on playgrounds.

Knowing more about what is happening in the neighbourhood and thus having access to information has been identified to lower the barrier for citizens to interact with each other and thus create a stronger community. Creating ways for citizens to share stories has been shown to strengthen the community $[81,85$, 86]. Therefore, the corresponding guideline states to increase information access on playgrounds, to foster social interaction between citizens.

Interaction guidelines. To elicit first interactions on the playground, location and physical surroundings are more important to consider than information. The scanning frequency data in the Tegelweetjes case study provided insights in the first interaction citizens will have with a playground. In this case, they spot the QR code and decide to scan it, and in that way access the virtual part of the playground (the website). The results highlighted that citizens arriving at the playground and spotting the QR code is far more important than the informational content provided. This is also reflected in other studies, which choose salient places [25] or use an eye-catching design [87] to stimulate interaction.

Our study confirms previous findings that citizens are especially eager to respond to information for which they can add with their personal experience $[86,88]$. To elicit interaction on playgrounds, it is thus vital to ensure citizens relate to the information and can add their own knowledge.

The last guideline is about the different ways citizens can interact with each other in the playground. The way information is offered has to allow citizens to refer to institutions, offer help, provide tips and make connections. This behaviour has been observed in the focus group and workshop but could not be noted for the Tegelweetjes case, as this system currently does not allow citizens to directly respond to the presented information.

\subsection{Grounding the guidelines in current discourse}

This paper started by reviewing the current discourse on playground design and stated the suggestions of other researchers for playground design. Playgrounds go beyond the notion of play that is only done for fun: playgrounds aim to use playful elements with a societal purpose, increasing social interactions between citizens and their engagement with the direct environment. Three main aspects for playground design were identified: location [74], information [45], and interaction [17]. The presented guidelines in this 
paper are grounded within these aspects, and further define how designers should deal with these aspects to create successful and engaging playgrounds for information sharing between citizens.

The contribution of this paper addresses the current knowledge gap on the underlying design considerations and principles for each of these playground aspects. The presented design guidelines make more explicit how designers can choose which locations are appropriate to become playgrounds, and which elements of a location should be considered. They also suggest which information topics citizens would like to discuss on these playgrounds, and how increased information sharing can support social interaction. Finally, the guidelines indicate how playgrounds can be designed to foster interaction, with the playgrounds itself and amongst citizens, and how citizens would like to interact with the information available on the playground. These guidelines thus extend the current knowledge on playground design, by making the considerations and principles for each playground aspect explicit and giving suggestions how designers need to deal with them.

\subsection{Limitations and future work}

The presented research identified guidelines based on three research activities. Albeit this setup allowed to study potential guidelines from different perspectives, there are some limitations and opportunities for future work. This research was performed in The Hague and the results, thus, have to be interpreted with this context in mind. Both the topics of interest and the locations can vary in other cities, especially outside of the western European environment. In order to develop these guidelines into design patterns [79], which will allow designers to use this playground solution over and over again, without ever doing it the same way twice, it is necessary to study more playground initiatives (like Tegelweetjes) in other cities. The guidelines then become design patterns for playgrounds that foster information sharing and social interaction between citizens.

An important finding is that citizens need to relate to the information and locations that are included in playgrounds. To gain an even deeper understanding of this relation, a next study, together with the initiator of Tegelweetjes, is planned to focus on the citizens' perspective on Tegelweetjes. In this study, a group of citizens will be invited on a city walk along various QR code tiles, to discuss what they think about the information and location. Furthermore, an application will be developed to allow for more elaborate interaction between citizens and the information on each tile.

\section{Conclusion}

Only with the engagement of citizen communities, cities worldwide can effectively deal with upcoming future transitions, ranging from digital transformation to migration $[1,2]$. However, in many big cities communities are fragmented [9] and neighbours do not interact with each other [10]. This research studied the city of The Hague which is the most fragmented city of The Netherlands [12, p. 52] and thus in need of finding ways to create engaged citizen communities. One of the ways this can be done is by considering the city from the perspective of a playable city $[16,17]$, where residents are empowered to participate.

However, there are many ways to transform a city into a playable one [17], and this paper proposed playgrounds as part of the playable city: physical and virtual environments where citizens can exchange information about the neighbourhood. Albeit many interventions for citizen empowerment in the playable city have been described in literature, the underlying assumptions and design choices are often not made explicit. Therefore, this research investigated which guidelines could be identified for designing playgrounds that foster local information sharing and neighbourhood participation.

The contribution of this paper is a set of eight guidelines, based on three different research activities performed in The Hague. These guidelines cover aspects of playgrounds like location, information, and interaction between citizens. The guidelines direct designers on how to select locations for playgrounds and which location characteristics to consider. They inform on which information topics are interesting for citizens and how interaction can be supported on these playgrounds. Some of these guidelines have been, in an implicit way, mentioned in other case studies, showing that these might extend the context of The Hague. However, future work is necessary to strengthen these guidelines with findings from other playground designs. Ultimately, these guidelines will develop into design patterns [79], which inform designers and researchers on how to create playgrounds in the city where residents will meet, interact, and collaborate on making the city a better place to live.

Acknowledgements. This research was initially part of the project BART! (www.bartportal.nl). We would like to express our gratitude to all citizens who participated in this research and the Municipality of The Hague for their (financial) support.

\section{References}

[1] Meerow, S., Newell, J.P. and Stults, M. (2016) Defining urban resilience: A review. Landscape and Urban Planning 147: 38-49. doi:10.1016/j.landurbplan.2015.11.011. 
[2] Comes, T. (2016) Designing for networked community resilience. Procedia Engineering 159: 6-11. doi:10.1016/j.proeng.2016.08.057.

[3] Adler, R.P., Goggin, J. and Bush, G.W. (2005) What Do We Mean By "Civic Engagement"? Journal of Transformative Education 3(3): 236-253. doi:10.1177/1541344605276792.

[4] Asad, M., Le Dantec, C.A., Nielsen, B. and Diedrick, K. (2017) Creating a Sociotechnical API: Designing CityScale Community Engagement. In Proceedings of the 2017 CHI Conference on Human Factors in Computing Systems (ACM): 2295-2306. doi:10.1145/3025453.3025963.

[5] De Lange, M. and de WAal, M. (2013) Owning the City: New Media and Citizen Engagement in Urban Design. First Monday 18(11): 1-13. doi:10.5210/fm.v18i11.4954.

[6] Hampton, K. and Wellman, B. (2003) Neighboring in Netville: How the Internet Supports Community and Social Capital in a Wired Suburb. City \& Community 2(4): 277-311. doi:10.1046/j.1535-6841.2003.00057.x.

[7] Adger, W.N. (2006) Vulnerability. Global Environmental Change 16(1): 268-281. doi:10.1016/j.gloenvcha.2006.02.006.

[8] Erete, S.L. (2015) Engaging Around Neighborhood Issues. In Proceedings of the 18th ACM Conference on Computer Supported Cooperative Work E Social Computing - CSCW '15: 1590-1601. doi:10.1145/2675133.2675182. 2675133.2675182.

[9] Gaventa, J. (2004) Representation, Community Leadership and Participation: Citizen Involvement in Neighbourhood Renewal and Local Governance. Tech. Rep. July, Office of Deputy Prime Minister. URL https://opendocs. ids.ac.uk/opendocs/bitstream/handle/20.500. 12413/12494/Gaventa\{_\}2004\{_\}representation. pdf ? sequence $=1$.

[10] Atkinson, R. and Kintrea, K. (2000) Owner-occupation, social mix and neighbourhood impacts. Policy and Politics 28(1): 93-108. doi:10.1332/0305573002500857.

[11] Voida, A., Harmon, E., Al-Ani, B. and Bren, D. (2012) Bridging Between Organizations and the Public: Volunteer Coordinators' Uneasy Relationship with Social Computing. In Proceedings of the SIGCHI Conference on Human Factors in Computing Systems (ACM): 1967-1976. doi:10.1145/2207676.2208341.

[12] Jennissen, R., Engbersen, G., Bokhorst, M. and Bovens, M. (2018) De nieuwe verscheidenheid. Toenemende diversiteit naar herkomst in Nederland. Tech. rep., Wetenschappelijke Raad voor het Regeringsbeleid, Den Haag. URL https://www. wrr.nl/publicaties/verkenningen/2018/05/29/ de-nieuwe-verscheidenheid.

[13] HaAg, G.D. (2019) The Hague Resilience Strategy. Tech. rep. URL www denhaag . buurtmonitor.nl.

[14] Fonseca, X., Lukosch, S. and Brazier, F. (2018) Social cohesion revisited: A new definition and how to characterize it. Innovation: The European Journal of Social Science Research (CIEJ) 32(2): 231-253. doi:10.1080/13511610.2018.1497480.

[15] Comes, T., Wijngaards, N. and Van de Walle, B. (2015) Exploring the future: Runtime scenario selection for complex and time-bound decisions. Technological Forecasting and Social Change 97: 29-46. doi:10.1016/j.techfore.2014.03.009.

[16] Nijholt, A. (2015) Designing humor for playable cities. Procedia Manufacturing 3: 2175-2182. doi:10.1016/j.promfg.2015.07.358.

[17] Nijholt, A. (2017) Playable Cities: The City as a Digital Playground (Singapore: Springer Science+Business Media). doi:10.1007/978-981-10-1962-3.

[18] Huizinga, J. (1949) Homo Ludens: A Study of the Playelement in Culture (London, UK: Routledge \& Kegan Paul Ltd).

[19] Lukosch, H.K., Bekebrede, G., Kurapati, S. and Luкоsch, S.G. (2018) A scientific foundation of simulation games for the analysis and design of complex systems. Simulation \& Gaming 49(3): 279-314. doi:10.1177/1046878118768858.

[20] Lukosch, H. and Comes, T. (2019) Gaming as a research method in humanitarian logistics. Journal of Humanitarian Logistics and Supply Chain Management 9(3): 352-370. doi:10.1108/JHLSCM-06-2018-0046.

[21] Oldenburg, R. (2001) Celebrating the Third Place: Inspiring Stories about the "Great Good Places" at the Heart of Our Communities (New York: Marlowe \& Company).

[22] Caldwell, G.A. and Foth, M. (2014) DIY Media Architecture: Open and Participatory Approaches to Community Engagement. In Proceedings of the 2nd Media Architecture Biennale Conference: World Cities: 110. doi:10.1145/2682884.2682893.

[23] Schroeter, R. (2012) Engaging New Digital Locals with Interactive Urban Screens to Collaboratively Improve the City. In Proceedings of the ACM 2012 conference on Computer Supported Cooperative Work (CSCW '12): 227236. doi:10.1145/2145204.2145239.

[24] Hespanhol, L., Tomitsch, M., McArthur, I., Fredericks, J., Schroeter, R. and Foth, M. (2015) Vote As You Go: Blending Interfaces For Community Engagement Into The Urban Space. In Proceedings of the 7th International Conference on Communities and Technologies - CET '15: 29-38. doi:10.1145/2768545.2768553.

[25] Balestrini, M., Marshall, P., Cornejo, R., Tentori, M., BIRD, J. and Rogers, Y. (2016) Jokebox: Coordinating Shared Encounters in Public Spaces. In Proceedings of the 19th ACM Conference on Computer-Supported Cooperative Work \& Social Computing (ACM): 38-49. doi:10.1145/2818048.2835203.

[26] Angus, A., Lane, G., Martin, K., West, N., Thelwall, S., Papadogkonas, D., Papamarkos, G. et al. (2008) Urban social tapestries. IEEE Pervasive Computing 7(4): 44-51. doi:10.1109/MPRV.2008.84.

[27] Campos, F. and Garcia, L. (2018) Fostering civic engagement through native maps: a preliminary study. In Interaction Design \& Children: 605-610. doi:10.1145/3202185.3210780.

[28] Slingerland, G., Mulder, I. and Jaskiewicz, T. (2019) Join the park!: Exploring opportunities to lower the participation divide in park communities. In Proceedings of the 9th International Conference on Communities E Technologies - Transforming Communities, C\&T '19 (ACM): 131-135. doi:10.1145/3328320.3328382.

[29] Schneider, H., Eiband, M., Ullrich, D. and Butz, A. (2018) Empowerment in HCI - A Survey and Framework. In Proceedings of the 2018 CHI Conference on Human 
Factors in Computing Systems - CHI '18: Paper 244. doi:10.1145/3173574.3173818.

[30] Rapport, N. (1996) Community. In Encyclopedia of Social and Cultural Anthropology.

[31] McMillan, D.W. and Chavis, D.M. (1986) Sense of community: A definition and theory. Special Issue: Psychological sense of community, I: Theory and concepts. Journal of Community Psychology 14(1): 6-23. doi:10.1002/1520-6629(198601)14:1<6::AIDJCOP2290140103>3.0.CO;2-I.

[32] Cohen, A.P. (2003) Symbolic Construction of Community (London: Routledge), 1st ed. doi:https://doi.org/10.4324/9780203131688.

[33] Овsт, P., Zinkiewicz, L. and Sмітн, S.G. (2002) Sense of community in science fiction fandom, part 1: Understanding sense of community in an international community of interest. Journal of Community Psychology 30(1): 87-103. doi:10.1675/1524-4695(2008)31.

[34] Wellman, B. (2005) Community: From neighborhood to Network. Communications of the ACM 48(10): 53-55. doi:10.1145/1089107.1089137.

[35] Mansuri, G. and Rao, V. (2004) Community-Based andDriven Development: A Critical Review. The Worldbank Observer 19(1): 1-39. doi:10.1093/wbro/lkh012.

[36] Wellman, B. and Wortley, S. (1990) Different Strokes from Different Folks: Community Ties and Social Support. American Journal of Sociology 96(3): 558-588. doi:10.1086/229572.

[37] Lane, G. (2003) Urban tapestries: Wireless networking, public authoring and social knowledge. Personal and Ubiquitous Computing 7(3-4): 169-175. doi:10.1007/s00779-003-0229-8.

[38] Kabeer, N. (1999) Resources, Agency, Achievements: Reflections on the Measurement of Women's Empowerment. Development and Change 30: 435-464. doi:10.1111/1467-7660.00125.

[39] Kleinhans, R., Van Ham, M. and Evans-Cowley, J. (2015) Using Social Media and Mobile Technologies to Foster Engagement and Self-Organization in Participatory Urban Planning and Neighbourhood Governance. Planning Practice and Research 30(3): 237-247. doi:10.1080/02697459.2015.1051320.

[40] Nelson, S. and Baldwin, N. (2002) Comprehensive Neighbourhood Mapping: Developing a Powerful Tool for Child Protection. Child Abuse Review 11(4): 214-229. doi:10.1002/car.741.

[41] Rizzo, F., Deserti, A. and Cobanli, O. (2016) Service Design in Public Sector: Boosting innovation through design. In Fifth Service Design and Innovation conference: 448-457. URL https://eprints.qut.edu.au/98712/ 1/HIDDEN_INNOVATION.pdf\#page $=12$.

[42] Pierce, J.L., Kostova, T. and Dirks, K.T. (2001) Toward a Theory of Psychological Ownership in Organizations. The Academy of Management Review 26(2): 298-310. doi:10.5465/amr.2001.4378028.

[43] Corbett, E. and Le Dantec, C.A. (2018) The Problem of Community Engagement: Disentangling the Practices of Municipal Government. In Proceedings of the $2018 \mathrm{CHI}$ Conference on Human Factors in Computing Systems: Paper 574. doi:10.1145/3173574.3174148.
[44] Taylor, N., Clarke, L., Skelly, M. and Nevay, S. (2018) Strategies for Engaging Communities in Creating Physical Civic Technologies. In Proceedings of the 2018 CHI Conference on Human Factors in Computing Systems (ACM): 1-12. doi:10.1145/3173574.3174081.

[45] Disalvo, C., Louw, M., Coupland, J. and Steiner, M. (2009) Local Issues, Local Uses: Tools for Robotics and Sensing in Community Contexts. In ACM Conference on Creativity and Cognition: 245-254. doi:10.1145/1640233.1640271.

[46] Aronson, B.R.E., Wallis, A.B., Campo, P.J.O. and Schafer, P. (2007) Neighbourhood mapping and evaluation: A methodology for participatory community health initiatives. The Maternal and Child Health Journal (11): 373-383.

[47] Tinati, R., Van Kleek, M., Simperl, E., Luczak-Roesch, M., Simpson, R. and Shadbolt, N. (2015) Designing for Citizen Data Analysis: A Cross-Sectional Case Study of a Multi-Domain Citizen Science Platform. In Proceedings of the 33rd Annual ACM Conference on Human Factors in Computing Systems (CHI '15): 4069-4078. doi:10.1145/2702123.2702420.

[48] Newman, G., Wiggins, A., Crall, A., Graham, E., Newman, S. and Crowston, K. (2012) The future of Citizen science: Emerging technologies and shifting paradigms. Frontiers in Ecology and the Environment 10(6): 298-304. doi:10.1890/110294.

[49] Dickinson, J.L., Shirk, J., Bonter, D., Bonney, R., Crain, R.L., Martin, J., Phillips, T. et al. (2012) The current state of citizen science as a tool for ecological research and public engagement. Frontiers in Ecology and the Environment 10(6): 291-297. doi:10.1890/110236.

[50] Mulder, I. (2012) Living Labbing the Rotterdam Way: Co-Creation as an Enabler for Urban Innovation Co-Creation as an Enabler for Urban Innovation. Technology Innovation Management Review 2(9): 39-43. doi:10.22215/timreview/607.

[51] Juujärvi, S. and Pesso, K. (2013) Actor Roles in an Urban Living Lab: What Can We Learn from Suurpelto, Finland? Technology Innovation Management Review 3(11): 22-27. doi:10.22215/timreview/742.

[52] O'sullivan, T.L., Corneil, W., Kuziemsky, C.E. and Toal-Sullivan, D. (2015) Use of the Structured Interview Matrix to Enhance Community Resilience Through Collaboration and Inclusive Engagement. Systems Research and Behavioral Science 32: 616-628. doi:10.1002/sres.2250.

[53] Hardy, K. and Comfort, L. (2014) Dynamic decision processes in complex, high-risk operations: The Yarnell Hill Fire, June 30, 2013. Safety Science 71: 39-47. doi:10.1016/j.ssci.2014.04.019.

[54] Arnstein, S.R. (1969) A Ladder Of Citizen Participation. Journal of the American Planning Association 35(4): 216-224. doi:10.1080/01944366908977225. arXiv: 1011. 1669v3.

[55] Cornwall, A. (2008) Unpacking 'Participation' Models, meanings and practices. Community Development Journal 43(3): 269-283. doi:10.1093/cdj/bsn 010.

[56] Mulder, I. (2014) Sociable smart cities: Rethinking our future through co-creative partnerships. In 
Streitz, N. and Markopoulos, P. [eds.] 2nd International Conference on Distributed, Ambient and Pervasive Interactions (Springer): 566-574. doi:10.1007/978-3319-07788-8_52.

[57] DAHL, R.A. (1994) A Democratic Dilemma: System Effectiveness versus Citizen Participation. Political Science Quarterly 109(1): 23-34. doi:10.2307/2151659.

[58] Arendt, H. (1958) The Human Condition (University of Chicago Press).

[59] Zimmerman, M.A. (1995) Psychological Empowerment: Issues and Illustrations. American Journal of Community Psychology 23(5): 581-599. doi:10.1007/BF02506983.

[60] Nam, T. and Pardo, T.A. (2011) Conceptualizing Smart City with Dimensions of Technology, People, and Institutions. In The Proceedings of the 12th Annual International Conference on Digital Government Research: 282-291. doi:10.1145/2037556.2037602.

[61] Yigitcanlar, T. and Velibeyoglu, K. (2008) KnowledgeBased Urban Development: The Local Economic Development Path of Brisbane, Australia. Local Economy 23(3): 195-207. doi:10.1080/02690940802197358.

[62] Lindskog, H. (2004) Smart communities initiatives. In Proceedings of the 3rd ISOneWorld Conference (Las Vegas): 1-16. URL https://www.heldag.com/articles/ smartcommunitiesapril2004.pdf.

[63] Le Dantec, C.A. and Fox, S. (2015) Strangers at the Gate: Gaining Access, Building Rapport, and CoConstructing Community-Based Research. In Proceedings of the 18th ACM Conference on Computer Supported Cooperative Work E Social Computing (ACM): 1348-1358. doi:10.1145/2675133.2675147.

[64] Ertner, M., Kragelund, A.M. and Malmborg, L. (2010) Five Enunciations of Empowerment in Participatory Design. In Proceedings of the 11th Biennial Participatory Conference (ACM): 191-194. doi:10.1145/1900441.1900475.

[65] Nijholt, A. (2017) Towards Playful and Playable Cities. In Nijholt, A. [ed.] Playable Cities: The City as a Digital Playground (Singapore: Springer Science+Business Media), chap. 1, 1-20. doi:10.1007/978-981-10-19623 .1.

[66] Peeters, M., Magens, C., Van den Hoven, E. and HumMELs, C. (2013) Social stairs: Taking the piano staircase towards long-term behavioral change. In International Conference on Persuasive Technology (Springer): 174-179. doi:10.1007/978-3-642-37157-8_21.

[67] Flanagan, M. (2009) Critical Play: Radical Game Design (Cambridge MA: MIT Press).

[68] Schouten, B., Ferri, G., de Lange, M. and Millenaar, K. (2017) Games as Strong Concepts for City-Making. In Nijholt, A. [ed.] Playable Cities: The City as a Digital Playground (Singapore: Springer Science+Business Media), 23-46. doi:10.1007/978-981-10-1962-3_2.

[69] Bateson, P. (2014) Play, playfulness, creativity and innovation. Animal Behavior and Cognition 1(2): 99-112. doi:10.12966/abc.05.02.2014.

[70] Caillois, R. (1961) Man, Play and Games (University of Illinois Press).

[71] Cila, N., Jansen, G., den Broeder, L., Groen, M., Meys, W. and Kröse, B. (2016) Look! A healthy neighbourhood: Means to motivate participants in using an app for monitoring community health. In Proceedings of the $2016 \mathrm{CHI}$ Conference Extended Abstracts on Human Factors in Computing Systems (ACM): 889-898. doi:10.1145/2851581.2851591.

[72] Fonseca, X., Lukosch, S., Lukosch, H., Tiemersma, S. and Brazier, F. (2017) Requirements and Game Ideas for Social Interaction in Mobile Outdoor Games. In CHI PLAY'17 Extended Abstracts (Amsterdam: ACM Press): 331-337. doi:10.1145/3130859.3131304.

[73] Fonseca, X., Lukosch, S. and Brazier, F. (2019) Fostering social interaction in playful cities. In BrooKs, A.L., Brooks, E. and Sylla, C. [eds.] Interactivity, Game Creation, Design, Learning, and Innovation (Springer International Publishing): 286-295. doi:10.1007/978-3030-06134-0_33.

[74] Bilandzic, M. and Foth, M. (2012) A review of locative media, mobile and embodied spatial interaction. International Journal of Human Computer Studies 70(1): 66-71. doi:10.1016/j.ijhcs.2011.08.004.

[75] Creswell, J.W. and Plano Clark, V.L. (2011) Choosing a Mixed Methods Design. In Designing and Conducting Mixed Methods Research, 53-106.

[76] Seawright, J. and Gerring, J. (2008) Case Selection Techniques Case Study Research Options. Political Research Quarterly 61(2): 294-308. doi:10.1177/1065912907313077.

[77] Teddlie, C. and Yu, F. (2007) Mixed Methods Sampling: A Typology with Examples. Journal of Mixed Methods Research 1(1): 77-100. doi:10.1177/1558689806292430. arXiv: $1011.1669 v 3$.

[78] Braun, V. and Clarke, V. (2006) Using Thematic Analysis in Psychology. Qualitative Research in Psychology 3(2): 77-101. doi:10.1191/1478088706qp063oa. arXiv : 1011. 1669v3.

[79] Alexander, C., Ishikawa, S., Silverstein, M., Jacobson, M., Fiksdahl-King, I. and Angel, S. (1977) A pattern language (New York: Oxford University Press).

[80] Brignull, H. and Rogers, Y. (2003) Enticing People to Interact with Large Public Displays in Public Spaces. In Human-Computer Interaction - INTERACT'03: 17-24.

[81] Allan, C., Dezuanni, M. and Mallan, K. (2017) Digital Storytelling for Community Participation: The Storyelling Social Living Lab. In Dezuanni, M., Foth, M., Mallan, K. and Hughes, H. [eds.] Digital Participation through Social Living Labs (Elsevier Ltd), 245-262. doi:10.1016/B978-0-08-102059-3.00013-7.

[82] KJeldskov, J. and PAAY, J. (2005) Just-for-us: a contextaware mobile information system facilitating sociality. In Proceedings of the 7th international conference on Human computer interaction with mobile devices $E$ services (MobileHCI '05): 23-30. doi:10.1145/1085777.1085782.

[83] Schuler, D. and Namioka, A. (1993) Participatory Design: Principles and Practices (CRC Press).

[84] Paulos, E., Jenkins, T., Joki, A. and Vora, P. (2008) Objects of wonderment. In Proceedings of the 7th ACM conference on Designing interactive systems (DIS '08): 350359. doi:10.1145/1394445.1394483.

[85] Han, K., Shih, P.C., Beth Rosson, M. and Carroll, J.M. (2016) Understanding Local Community Attachment, Engagement and Social Support Networks Mediated by Mobile Technology. Interacting with Computers 28(3): 
220-237. doi:10.1093/iwc/iwu040.

[86] Dezuanni, M. and Allan, C. (2017) Pittsworth Stories: Developing a Social Living Lab for Digital Participation in a Rural Australian Community. In Dezuanni, M., Foth, M., Mallan, K. and Hughes, H. [eds.] Digital Participation through Social Living Labs (Elsevier Ltd), chap. 10, 191-205. doi:10.1016/B978-0-08102059-3.00010-1.

[87] Crivellaro, C., Taylor, A., Vlachokyriakos, V., Comber, R., Nissen, B. and Wright, P. (2016) ReMaking Places: HCI, 'Community Building' and
Change. In Proceedings of the 2016 CHI Conference on Human Factors in Computing Systems: 2958-2969. doi:10.1145/2858036.2858332.

[88] Disalvo, C., Illah Nourbakhsh, D., Holstius, A.A. and Luow, M. (2008) The Neighborhood Networks Project: A Case Study of Critical Engagement and Creative Expression Through Participatory Design. In Tenth Anniversary Conference on Participatory Design 2008 (ACM): 41-50. 